\title{
Study on technological properties of winter wheat soils
}

\author{
Hamrokul Ravshanov ${ }^{1 *}$, Farmon Mamatov ${ }^{1,2}$, Odil Primov ${ }^{1}$, Shakhnoza Khazratkulova ${ }^{1}$ \\ and Dilshod Baratov ${ }^{3}$ \\ ${ }^{1}$ Karshi branch of Tashkent Institute of Irrigation and Agricultural Mechanization Engineers, Karshi, \\ 180119, Uzbekistan \\ ${ }^{2}$ Karshi Engineering Economic Institute, Karshi, 180100, Uzbekistan \\ ${ }^{3}$ Tashkent Institute of Irrigation and Agricultural Mechanization Engineers, Tashkent, 100000, \\ Uzbekistan
}

\begin{abstract}
The aim of the study is to study and analyze the physical, mechanical and technological properties of soils from under winter grain crops in the hot climate of Uzbekistan. The results of determining the moisture content, density, hardness and resistance to various deformations of soils after harvesting winter wheat are presented. The basic principles and methods of classical mechanics, mathematical analysis and statistics were used in this study. Studies have found that, in the layer $0-30$, the soil moisture for ten days after harvesting winter cereals decreases by $12.1-16.3 \%$, and the soil hardness increases by $10.7-16.4 \%$ and are 3.22-5.14 MPa. At the same time, at an average humidity of $12-14 \%$, the resistance of the soil to breakage and torsion, respectively, is 1.3-1.8 and 1.0-1.1 times higher than the resistance of the soil to shear. The resistance of the soil to shear is $87.9 \mathrm{kPa}$, and to breakage and torsion-69.7 and $78.6 \mathrm{kPa}$, respectively.
\end{abstract}

\section{Introduction}

In the zone of Uzbekistan, tillage from under grain crops is carried out in July-August. During this period, the topsoil compacted by tractors and harvesters is severely dried up. The moisture content of the top layer is reduced to $5 \%$, and the hardness is reduced to 11.8 $\mathrm{MPa}$ [1]. Therefore, when processing soils that are prone to clumping, plowing turns out to be coarse-grained. The precipitation that fell in the winter and early spring periods on such soil quickly evaporates. K. M. Mansurov [1], M. Muradov [2], O. R. Kenzhaev [3], V. I. Kravchenko [4], F. M. Mamatov [5, 6, 7], and I. T. Ergashev studied the physical and mechanical properties during the main tillage at various times $[5,6,8,9]$, B. S. Mirzaev [6, 7, 10-24], D. Chuyanov [11, 25], H. Ravshanov [10-12, 23, 26, 27, 28], H. Fayzullaev [11, $26,28,29,30]$ and others. The most interesting are the studies of the physical and mechanical properties of soils conducted by K. M. Mansurov [1]. He studied the moisture content, density, hardness of the arable layer, tear resistance, compression and friction of the upper horizon of takyr soils and light gray soils. It is established that the value of the soil hardness depends on the agrotechnical background, humidity and depth of immersion

*Corresponding author: ravshanovhamroqul@mail.ru 


\section{ICECAE 2021}

of the plunger. The lowest soil hardness was observed in the horizon of $0-5 \mathrm{~cm}$ of the arable layer, and the highest hardness at a depth of 10-20 cm. M. M. Muradov [2] as a result of studies, they conclude that the soil in the sub-arable horizon (at a depth of 50-60 cm), compared with the arable one, has lower humidity, greater hardness and high coefficients of soil friction against metal. The analysis of the conducted studies shows that the physical, mechanical and technological properties of soils from under winter grain crops in a hot climate are not sufficiently studied.

The aim of the study is to study and analyze the physical, mechanical and technological properties of soils from under winter grain crops in the hot climate of Uzbekistan.

\section{Methods}

The basic principles and methods of classical mechanics, mathematical analysis and statistics were used in this study.

Studies of the physical, mechanical and technological properties of soils from winter grain crops were conducted in the Kashkadarya region of Uzbekistan. The density and humidity of the soil were determined by sampling with the Litvinov device. The resistance of the soil to various deformations was determined using a reconstructed device by the authors (Fig. 1). When determining the resistance of the soil to tear and tear, a bottomless box 4 with a size of $100 \times 100 \times 50 \mathrm{~mm}$ is pressed into the soil. The soil around the box 4 is carefully removed to prevent friction. When the handle 2 rotates, the cord 5 , winding on the pulley 3 , through the pulley 6 drags the rod 8 along with it, compressing the spring 9 . The nature of the change in the separation force is recorded with a pencil 7 on a paper tape wound on the drum 10 .

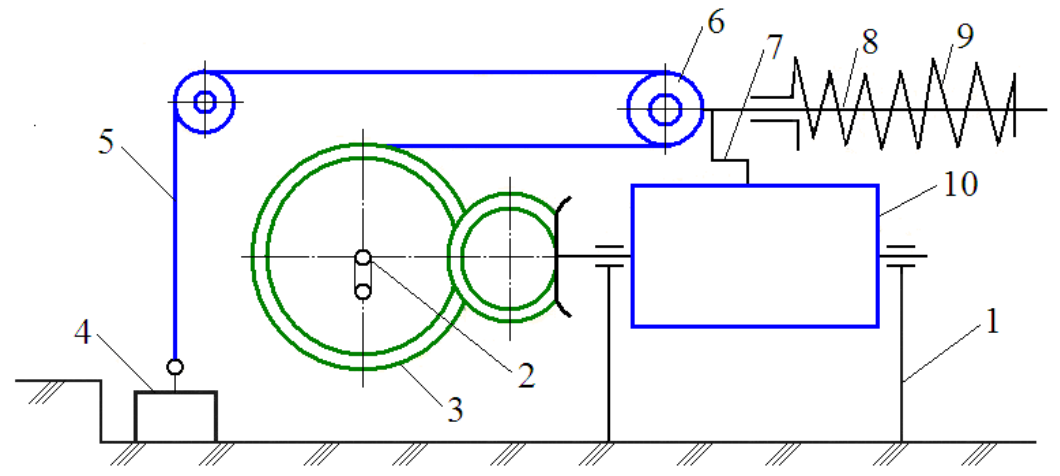

a)

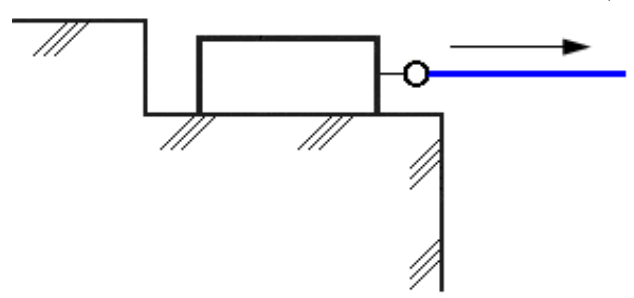

b)

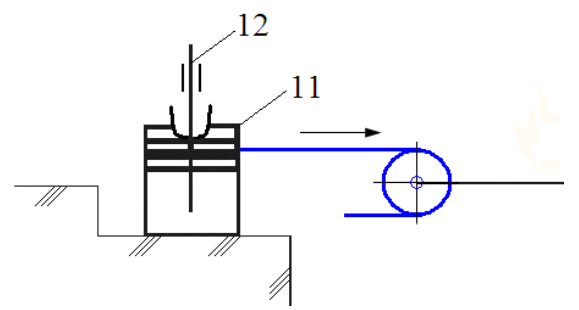

c)

Fig.1. Scheme for determining the resistance of the soil to rupture (a), shear $(b)$ and torsion $(c)$

The tensile strength of the soil was determined by the following formula

$$
K_{r}=\frac{P_{s t}-G}{F}
$$


where $P_{\mathrm{st}}$ - the force of separation of the soil from the base; $G$ - the weight of the soil in the box; $F$ - the area of the torn part of the sample.

The shear resistance (ultimate strength) of the soil was determined by the following formula

$$
K_{c d}=\frac{P_{c d}}{F}
$$

where $P_{\mathrm{cd}}-$ is the shear force of the soil from the base.

To determine the torsion resistance of the soil, a special cylinder 11 with an internal diameter of $100 \mathrm{~mm}$ was made. When determining the torsion resistance of the soil, the cylinder 11 with the cord 5 wound on it is pressed into the soil. Then the soil around cylinder 5 is removed. When the handle 2 rotates, the cord 5 is wound on the pulley 3 , and overcoming the force of the spring 9 , it moves the rod. In this case, the torsion force of the cylinder with the soil is fixed on the tape of the device.

The torsional resistance (ultimate strength) of the soil is determined by the following formula

$$
K_{k r}=\frac{P_{k r}-P_{s}}{F}
$$

where $P_{k r}$ - is the force of rolling the cylinder with soil; $P_{s}-$ is the force of rolling the cylinder without soil.

\section{Results}

After the fall grain harvest, soil moisture and density were studied for several days in a row before the repeated crops were prepared for planting. Soil moisture, density, and hardness values were determined at a depth of $0-50 \mathrm{~cm}$ in every $10 \mathrm{~cm}$ of soil layer (Table 1).

Table 1. Soil moisture values for 10 days after winter grain harvesting, $\%$

\begin{tabular}{|c|c|c|c|c|c|c|}
\hline \multirow{2}{*}{ Soil layer. cm } & \multicolumn{6}{|c|}{ Soil moisture after winter grain harvesting } \\
\cline { 2 - 7 } & 1-day & 2-day & 3 -day & 5 -day & 7-day & 10 - day \\
\hline $0-10$ & 9.8 & 9.3 & 8.8 & 8.5 & 8.4 & 8.2 \\
\hline $10-20$ & 11.6 & 10.8 & 10.6 & 10.5 & 10.3 & 10.2 \\
\hline $20-30$ & 12.8 & 12.7 & 12.4 & 12.3 & 12.1 & 12.1 \\
\hline $30-40$ & 12.6 & 12.4 & 12.2 & 11.9 & 11.9 & 11.9 \\
\hline $40-50$ & 11.9 & 11.8 & 11.8 & 11.6 & 11.7 & 11.5 \\
\hline
\end{tabular}

According to Table 1, in areas free of autumn cereals, soil moisture changes rapidly over days. For example, in the $0-10 \mathrm{~cm}$ layer, the humidity decreased from $9.8 \%$ to $8.2 \%$ in 10 days, which is $16.3 \%$ less than in the first day. In the $10-20 \mathrm{~cm}$ layer of soil, the decrease was $12.1 \%$, in the $20-30 \mathrm{~cm}, 30-40 \mathrm{~cm}$ layers $5.5 \%$, and in the $40-50 \mathrm{~cm}$ layer $3.3 \%$. This means that under the influence of hot weather, moisture is lost quickly in the upper layers of the soil, and in the lower layers, the decrease in moisture is slower due to the upper layer. Soil moisture decreases rapidly within 3 days after harvest of autumn cereals. This decrease was $10.2 \%$ relative to the moisture content of the first day in the $0-10 \mathrm{~cm}$ soil layer, $8.6 \%$ in the $10-20 \mathrm{~cm}$ layer, $3.1 \%$ in the $20-30 \mathrm{~cm}, 30-40 \mathrm{~cm}$ layer, and $40-50 \mathrm{~cm}$ layer. while $0.84 \%$. Over the next 7 days, the decrease in soil moisture in these layers was $6.8 \%$, respectively; $3.8 \% ; 2.4 \%$ and $2.5 \%$, respectively.

Table 2 shows the dynamics of changes in soil density in the first ten days after the autumn grain harvest. The soil type is light gray. According to Table 2, the density of irrigated soils does not change significantly in any layer over days. Differences in density values are not 
larger than experimental errors. However, the density varies depending on the depth of the soil layers. Fig. 2 shows the changes in moisture and density at different depths of the soil.

Table 2. Soil density values within 10 days after winter grain harvesting, $\mathrm{g} / \mathrm{cm}^{3}$

\begin{tabular}{|c|c|c|c|c|c|c|c|}
\hline \multirow{2}{*}{$\begin{array}{c}\text { Soil layer, } \\
\text { cm }\end{array}$} & $\begin{array}{c}\text { Average } \\
\text { humidity } \\
\text { value, } \\
\text { \% }\end{array}$ & \multicolumn{4}{|c|}{ Soil hardness after winter grain harvesting } \\
\cline { 3 - 8 } & 1-day & 2-day & 3-day & 5-day & 7-day & 10-day \\
\hline $0-10$ & 8.8 & 1.23 & 1.22 & 1.23 & 1.23 & 1.22 & 1.23 \\
\hline $10-20$ & 10.5 & 1.32 & 1.32 & 1.33 & 1.32 & 1.31 & 1.33 \\
\hline $20-30$ & 12.2 & 1.44 & 1.42 & 1.41 & 1.46 & 1.43 & 1.42 \\
\hline $30-40$ & 12.0 & 1.50 & 1.52 & 1.51 & 1.50 & 1.49 & 1.51 \\
\hline $40-50$ & 11.5 & 1.39 & 1.37 & 1.37 & 1.39 & 1.40 & 1.38 \\
\hline
\end{tabular}

According to Fig.2, soil moisture has the highest value (12.2\%) at a depth of $20-30 \mathrm{~cm}$. Its value is $27.8 \%$ more than $0-10 \mathrm{~cm}, 13.9 \%$ more than $10-20 \mathrm{~cm}, 1.64 \%$ more than $30-40 \mathrm{~cm}$ and $5.7 \%$ more than $40-50 \mathrm{~cm}$. ldi. The density of the soil is the highest in the $30-40 \mathrm{~cm}$ layer $\left(1.51 \mathrm{~g} / \mathrm{cm}^{3}\right)$. The density of the $30-40 \mathrm{~cm}$ layer of soil is $19.2 \%$ relative to the $0-10$ $\mathrm{cm}$ layer, $12.6 \%$ relative to the $10-20 \mathrm{~cm}$ layer, $5.3 \%$ relative to the $20-30 \mathrm{~cm}$ layer, and 8 relative to the $40-50 \mathrm{~cm}$ layer; More than $6 \%$.

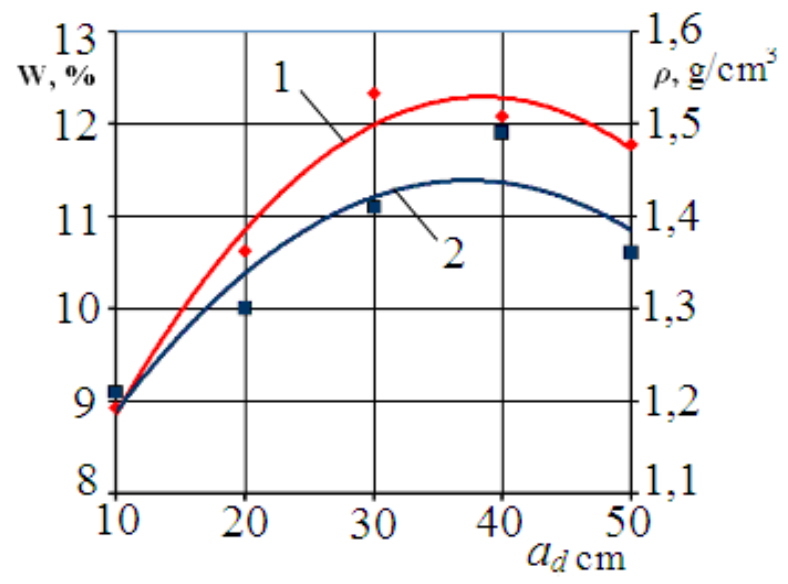

Fig.2. Graphs of the dependence of humidity $(W)$ and density $(\rho)$ of light gray earths depending on the depth of horizons $\left(a_{d}\right): 1$ - humidity; 2 - density

Soil hardness is an important indicator that depends on its mechanical composition and moisture, the amount of organic matter in it, the type of crop grown, the depth of pretillage, the drag resistance of working tools during tillage and the degree of soil erosion. is calculated.

The dynamics of changes in soil hardness in the first ten days after the autumn grain harvest were studied. Studies have shown that soil hardness values fluctuate and increase with time (Table 3).

According to Table 3, the soil hardness in 10 days in the $0-10 \mathrm{~cm}$ layer is $16.4 \%$ compared to the hardness in the first day, $10.7 \%$ in the soil layer at a depth of $10-20 \mathrm{~cm}$, and $7.9 \%$ in the soil layer at a depth of $20-30 \mathrm{~cm}$. ha, by $6.2 \%$ in the soil layer at a depth of $30-40 \mathrm{~cm}$, and by $3.1 \%$ in the soil layer at a depth of $40-50 \mathrm{~cm}$. In this case, the hardness in the upper 
layers of the soil increases rapidly, and in the lower layers of the soil changes slowly accordingly.

Table 3. Values of soil hardness within 10 days after harvesting of winter grain, Mpa

\begin{tabular}{|c|c|c|c|c|c|c|}
\hline \multirow{2}{*}{ Soil layer. cm } & \multicolumn{5}{|c|}{ Soil hardness after winter grain harvesting } \\
\cline { 2 - 7 } & 1-day & 2-day & 3-day & 5-day & 7-day & 10-day \\
\hline $0-10$ & 2.69 & 2.72 & 2.76 & 2.90 & 3.06 & 3.22 \\
\hline $10-20$ & 3.73 & 3.76 & 3.83 & 3.92 & 4.03 & 4.18 \\
\hline $20-30$ & 4.64 & 4.70 & 4.76 & 4.85 & 4.94 & 5.04 \\
\hline $30-40$ & 5.53 & 5.60 & 5.65 & 5.76 & 5.83 & 5.90 \\
\hline $40-50$ & 4.98 & 4.50 & 5.04 & 5.07 & 5.09 & 5.14 \\
\hline
\end{tabular}

The hardness of the soil reached its maximum value $(5.70 \mathrm{MPa})$ at a depth of $30-40 \mathrm{~cm}$. In this case, it is $49.2 \%$ of the soil layer at a depth of $0-10 \mathrm{~cm}, 31.7 \%$ of the soil layer at a depth of $10-20 \mathrm{~cm}, 15.6 \%$ of the soil layer at a depth of $20-30 \mathrm{~cm}$ and $40-50 \mathrm{~cm}$ of soil. had a stiffness of $12.9 \%$ more than the stratum.

Soil hardness decreases after a depth of $30-40 \mathrm{~cm}$. This is because the aggregates have little effect on the compaction of the underlying soil layers.

We have determined the resistance of the soil to rupture, shear and torsion (Table 4). The data show that the resistance of the soil to various deformations has the highest values in the soil layer at a depth of $15-20 \mathrm{~cm}$. This is because when the humidity is low $(8-10 \%)$, the hardness of the soil increases and its resistance to breakage and displacement increases.

In soils with sufficient moisture, there are water shells around its molecules. They reduce the torsional and shear resistance of the soil. However, an increase in moisture leads to an increase in the torsional resistance of the soil.

According to Table 4, in the 0-30 cm deep layer of soil, its shear resistance is $1.3-1.8$ and 1.0-1.1 times higher than the shear and torsional resistance, respectively. In fields devoid of autumn cereals, the average soil moisture is $12-14 \%$, its shear strength is $87.9 \mathrm{kPa}$, and shear and torsional strength is 69.7 and $78.6 \mathrm{kPa}$. As the moisture content decreases, the resistance of the soil to breakage and shear increases rapidly. The torsional strength of the soil changes gradually.

Table 4. Resistance of the soil of light gray soils from under winter cereals to various deformations

\begin{tabular}{|c|c|c|c|c|}
\hline Soil layer, cm & Humidity, \% & Gap, kPa & Shift, kPa & Torsion, kPa \\
\hline $0-5$ & \multirow{2}{*}{8.9} & 39.4 & 71.5 & 63.6 \\
\hline $5-10$ & & 62.5 & 79.6 & 73.0 \\
\hline $10-15$ & \multirow{2}{*}{10.6} & 75.6 & 93.3 & 80.0 \\
\hline $15-20$ & & 78.5 & 96.6 & 81.4 \\
\hline $20-25$ & \multirow{2}{*}{12.4} & 78.1 & 91.7 & 82.7 \\
\hline $25-30$ & & 70.3 & 89.3 & 84.0 \\
\hline $30-35$ & \multirow{2}{*}{12.2} & 73.5 & 87.5 & 81.4 \\
\hline $35-40$ & & 80.0 & 94.4 & 82.9 \\
\hline
\end{tabular}

Thus, the physico-mechanical and technological properties of soils in irrigated areas freed from fall grain crops for replanting show that when moisture content is low, the soil has high strength and a large amount of energy in their cultivation.

\section{Conclusions}

1. Studies have found that, in the layer 0-30, the soil moisture for ten days after harvesting winter cereals decreases by $12.1-16.3 \%$, and the soil hardness increases by $10.7-16.4 \%$ and is $3.22-5.14 \mathrm{MPa}$. 
2. At an average humidity of $12-14 \%$, the resistance of the soil to breakage and torsion, respectively, is 1.3-1.8 and 1.0-1.1 times higher than the resistance of the soil to shear. The resistance of the soil to shear is $87.9 \mathrm{kPa}$, and to breakage and torsion-69.7 and $78.6 \mathrm{kPa}$, respectively.

\section{References}

1. K. M. Mansurov, Research of the main tillage processes in the Karshi steppe zone in order to improve agrotechnical indicators, Candidate of Science Dissertation, Yangi Yul, Tashkent (1975)

2. M. M. Muradov, R. I. Bajmetov, N. S. Bibutov, Mechanics and technological fundamentals and parameters of tools for soil decompaction, Uzbek Academy of Sciences, Tashkent (1988)

3. O. R. Kenzhaev, Influence of the number of passes of tractor units on soil density and cotton yield, Scientific Technical Bulletin 5 19-22 (1989)

4. V. I. Kravchenko, Soil compaction with machines, Science, Almaty (1986)

5. F. Mamatov, I. Ergashev, S. Ochilov, X. Pardaev, Traction Resistance of Soil Submersibility Type "Paraplau", J. Adv Research in Dynamical \& Control Systems 12 , 2154-2161 (2020)

6. F. Mamatov, I. Ergashev, B. Mirzaev, X. Pardaev, D. Chorieva, Research of the Penetration Process of the Frontal Plow, Journal of Physics: Conference Series 1779, 012002 (2021).

7. F. M. Mamatov, B. S. Mirzaev, I. Zh. Avazov, Agrotechnical foundations for the creation of anti-erosion moisture-saving technical means of soil cultivation in the conditions of Uzbekistan, Environmental Management, Moscow (2014)

8. N. Aldoshin, F. Mamatov, I. Ismailov, G. Ergashov, Development of combined tillage tool for melon cultivation, In Proceedings: 19th International Conference on Engineering for Rural Development, Jelgava, 19, (2020).

9. B. Mirzaev, F. Mamatov, I. Ergashev, Yo. Islomov, B. Toshtemirov, O. Tursunov, Restoring degraded rangelands in Uzbekistan, Procedia Environmental Science, Engineering and Management 6, 395-404 (2019)

10. U. Umurzakov, B. Mirzaev, F. Mamatov, H. Ravshanov, Sh. Kurbonov, A rationale of broach-plow's parameters of the ridge-stepped ploughing of slopes, IOP Conf. Series: Earth and Environmental Science 403, 012163 (2019)

11. B. Mirzaev, F. Mamatov, D. Chuyanov, X. Ravshanov, G. Shodmonov, R. Tavashov, X. Fayzullayev, Combined machine for preparing soil for cropping of melons and gourds, IOP Conf. Ser.: Earth Environ. Sci. 403, 012158 (2019)

12. B. Mirzaev, F. Mamatov, I. Ergashev, H. Ravshanov, Sh. Mirzaxodjaev, Sh. Kurbanov, U. Kodirov, G. Ergashev, Effect of fragmentation and pacing at spot ploughing on dry soils, E3S Web of Conferences 97, 01065 (2019).

13. F. Mamatov, B. Mirzaev, M. Shoumarova, P. Berdimuratov, D. Khodzhaev, Comb former parameters for a cotton seeder, Int J Engineering and Advanced Technology 9 , 4824-4826 (2019).

14. F. Mamatov, B. Mirzaev, Z. Batirov, S. Toshtemirov, O. Tursunov, L. Bobojonov, Justification of machine parameters for ridge forming with simultaneous application of fertilizers, IOP Conf. Series: Materials Science and Engineering 883, 012165 (2020)

15. B. Mirzaev, F. Mamatov, I. Avazov, S. Mardonov, Technologies and technical means for anti-erosion differentiated soil treatment system, E3S Web of Conferences 97, 05036 (2019) 
16. N. Aldoshin, O. Didmanidze, B. Mirzayev, F. Mamatov, Harvesting of mixed crops by axial rotary combines, In Proceeding: $7^{\text {th }}$ International Conference on Trends in Agricultural Engineering 2019, Prague, Czech Republic, pp. 20-26 (2019)

17. B. Mirzaev, F. Mamatov, N. Aldoshin, M. Amonov, Anti-erosion two-stage tillage by ripper, In Proceedings: 7th International Conference on Trends in Agricultural Engineering, Prague, Czech Republic, pp. 391-396 (2019)

18. F. Mamatov, B. Mirzaev, P. Berdimuratov, Kh. Turkmenov, L. Muratov, G. Eshchanova, The stability stroke of cotton seeder moulder, IOP Conf. Series: Materials Science and Engineering 883, 012145 (2020)

19. F. Mamatov, B. Mirzaev, O. Tursunov, A Justification of Broach-Plow's Parameters of the Ridge-Stepped Ploughing, E3S Web of Conferences 97, 05035 (2019)

20. F. Mamatov, B. Mirzaev, O. Tursunov, S. Ochilov, D. Chorieva, Relief, physicomechanical and technological properties of soil in the cotton growing area, IOP Conf. Series: Earth and Environmental Science 614, 012169 (2020)

21. Z. Shamsutdinov, Sh. Ubaydullaev, N. Shamsutdinov, B. Mirzaev, F. Mamatov, N. Chorshabiyev, The concept of the phytogenic field: theory, research experience and practical significance, IOP Conf. Series: Earth and Environmental Science 614, 012164 (2020)

22. U. Umurzakov, F. Mamatov, N. Aldoshin, B. Mirzaev, Exploration of tillage technologies in the Republic of Uzbekistan, IOP Conf. Series: Earth and Environmental Science 614, 012168 (2020).

23. F. Mamatov, N. Aldoshin, B. Mirzaev, H. Ravshanov, Sh. Kurbanov, N. Rashidov, Development of a frontal plow for smooth, furless plowing with cutoffs, IOP Conf. Series: Materials Science and Engineering 1030, 012135 (2021).

24. F. Mamatov, B. Mirzaev, Sh. Mirzahodzhaev, Z. Uzakov, D. Choriyeva, Development of a front plow with active and passive working bodies, IOP Conf. Series: Materials Science and Engineering 1030, 012164 (2021)

25. D. Chuyanov, G. Shodmonov, I. Avazov, N. Rashidov, S. Ochilov, Soil preparation machine parameters for the cultivation of cucurbitaceous crops, IOP Conf. Series: Materials Science and Engineering 883, 012139 (2020)

26. Kh. Ravshanov, Kh. Fayzullaev, I. Ismoilov, D. Irgashev, S. Mamatov, The machine for the preparation of the soil in sowing of plow crops under film, IOP Conf. Series: Materials Science and Engineering 883, 012138 (2020)

27. H. Ravshanov, L. Babajanov, Sh. Kuziev, N. Rashidov, Sh. Kurbanov, Plough hitch parameters for smooth tails, IOP Conf. Series: Materials Science and Engineering $\mathbf{8 8 3}, 012139$ (2020)

28. I. Temirov, Kh. Ravshanov, Kh. Fayzullaev, Sh. Ubaydullaev, U. Kodirov, Development of a machine for preparing the soil for sowing melons under the film IOP Conf. Series: Materials Science and Engineering 1030, 012169 (2021).

29. U. Kodirov, N. Aldoshin, Sh. Ubaydullayev, E. Sharipov, Z. Muqimov, B. Tulaganov, The soil preparation machine for seeding potatoes on comb, IOP Conf. Series: Materials Science and Engineering 883, 012143 (2020)

30. Kh. Fayzullayev, S. Mamatov, M. Radjabov, Sh. Sharipov, R. Tavashov, M. Nurmanova, The quality of loosening the soil with subsoilers of the combined machine, IOP Conf. Series: Materials Science and Engineering 1030, 012171 (2021). 